\title{
An evaluation of non-metric cranial traits used to estimate ancestry in a South African sample
}

\author{
E.N. L'Abbé ${ }^{a, *}$, C. Van Rooyen ${ }^{\text {a }}$, S.P. Nawrocki ${ }^{b}$, P.J. Becker ${ }^{\text {a,c }}$ \\ ${ }^{a}$ Department of Anatomy, Faculty of Health Sciences, University of Pretoria, P.O. Box 2034, Pretoria 0001, South Africa \\ ${ }^{\mathrm{b}}$ Department of Biology, University of Indianapolis, 1400 E Hanna Avenue, Indianapolis, IN 46227-3697, United States \\ ${ }^{\mathrm{c} B i o s t a t i s t i c s}$ Unit, Medical Research Council, South Africa
}

\section{A R T I C L E I N F O}

\section{Article history:}

Received 6 August 2010

Received in revised form 6 March 2011

Accepted 3 April 2011

Available online $\mathrm{xxx}$

\section{Keywords:}

South Africa

Ordinal regression statistics

Sex

Age at death

Pretoria Bone Collection

Human variation

\begin{abstract}
A B S T R A C T
Establishing ancestry from a skeleton for forensic purposes has been shown to be difficult. The purpose of this paper is to address the application of thirteen non-metric traits to estimate ancestry in three South African groups, namely White, Black and "Coloured”. In doing so, the frequency distribution of thirteen non-metric traits among South Africans are presented; the relationship of these non-metric traits with ancestry, sex, age at death are evaluated; and Kappa statistics are utilized to assess the inter and intrarater reliability. Crania of 520 known individuals were obtained from four skeletal samples in South Africa: the Pretoria Bone Collection, the Raymond A. Dart Collection, the Kirsten Collection and the Student Bone Collection from the University of the Free State. Average age at death was 51, with an age range between 18 and 90 . Thirteen commonly used non-metric traits from the face and jaw were scored; definition and illustrations were taken from Hefner [2], Bass [6] and Hauser and De Stephano [7]. Frequency distributions, ordinal regression and Cohen's Kappa statistics were performed as a means to assess population variation and repeatability. Frequency distributions were highly variable among South Africans. Twelve of the 13 variables had a statistically significant relationship with ancestry. Sex significantly affected only one variable, inter-orbital breadth, and age at death affected two (anterior nasal spine and alveolar prognathism). The interaction of ancestry and sex independently affected three variables (nasal bone contour, nasal breadth, and interorbital breadth). Seven traits had moderate to excellent repeatability, while poor scoring consistency was noted for six variables. Difficulties in repeating several of the trait scores may require either a need for refinement of the definitions, or these character states may not adequately describe the observable morphology in the population. The application of the traditional experience-based approach for estimating ancestry in forensic case work is problematic.
\end{abstract}

(c) 2011 Elsevier Ireland Ltd. All rights reserved.

\section{Introduction}

Establishing ancestry from a skeleton for forensic and other purposes has been shown to be difficult, with several researchers advocating for a revision in the traditional non-metric methodology $[1,2]$. While the typological experience-based approach to evaluate ancestry has been undermined $[2,3]$, more research is needed to demonstrate geographic patterning and variation in human populations. Knowledge of population variation is necessary for the improvement of techniques used to address ancestry in forensic anthropology. The purpose of this paper is to address the application of thirteen non-metric traits to estimate ancestry in three socially defined South African groups, namely White, Black

\footnotetext{
* Corresponding author. Tel.: +27 12319 2438/82 213 2285; fax: +27 123192240

E-mail address: ericka.labbe@up.ac.za (E.N. L’Abbé).
}

and "Coloured". In doing so, the frequency distribution of thirteen non-metric traits among South Africans are presented; the relationship of these non-metric traits with ancestry, sex, age at death are evaluated; and Kappa statistics are utilized to assess the inter and intra-rater reliability.

When compared to other groups from Europe or Asia, South Africans can be considered heterogenous. According to population estimates (http://www.statssa.gov.za/), South Africa is home to more than 49 million people of diverse origins, cultures, languages and beliefs. These people are socially classified into four main groups, namely Black, White, "Coloured" and Indian/Asian. Indigenous Africans (Blacks) are in the majority at just over 38 million and make up $79.6 \%$ of the population, while Whites are estimated at 4.3 million (9.1\%), "Coloureds" 4.2 million (8.9\%), and Indian/Asian groups 1.2 million (2.5\%). Of the 11 official languages, ten are African-based and one is European (English).

Black South Africans can be divided into two main groups: the Nguni, comprising the Zulu, Xhosa, Ndebele and Swazi; and the 
Table 1

South African sample by sex and ancestry.

\begin{tabular}{|c|c|c|c|c|c|c|}
\hline & \multicolumn{2}{|c|}{ White $(n=158)$} & \multicolumn{2}{|c|}{ Black $(n=237)$} & \multicolumn{2}{|c|}{ "Coloured" $(n=125)$} \\
\hline & Male & Female & Male & Female & Male & Female \\
\hline University of Pretoria & 32 & 15 & 100 & 41 & 0 & 0 \\
\hline University of Stellenbosch & 1 & 1 & 12 & 2 & 61 & 22 \\
\hline University of the Free State & 0 & 0 & 23 & 9 & 0 & 0 \\
\hline University of Witwatersrand & 61 & 48 & 0 & 50 & 26 & 16 \\
\hline Total & 94 & 63 & 135 & 102 & 87 & 38 \\
\hline
\end{tabular}

Sotho-Tswana, which includes the Southern, Northern and Western Sotho (Tswana), the Tsonga and the Venda. White South Africans descend largely from colonial immigrants of the late 17th, 18th and 19th centuries and included European groups such as the British, Dutch, German, and French Huguenots. "Coloured" and brown are social terms used to define - both culturally and socially - persons who descended from slaves brought in from the East and Central Africa, Malaysia, the indigenous Khoisan who live in the Cape, as well as modern black and white people. Despite their various origins, South African Coloureds are considered a distinct population group.

Brace and Hunt [4] suggested that non-metric traits associated with ancestry were manufactured in America and that the application and interpretation of methods based on these traits are not exportable to other countries or populations [4]. While Brace and Hunt's comment was to act as a deterrent to researchers investigating differences among populations, it has, perhaps unintentionally, also provided justification for this type of research. In South Africa, law enforcement and forensic pathologists frequently request a social classification, such as Black, White, or "Coloured", from the biological remains of an unidentified person.

Yet, medicolegal investigators and anthropologists have little understanding of human variation in the country and the meaning behind providing an ancestry designation to a set of skeletal remains. With current research trends focused on the accuracy and reliability of anthropological methods, the question has arisen as to whether these non-metric traits can be meaningfully used to distinguish White, Black and "Coloured" South Africans. The results of these inquiries have direct implications for the use of these methods for forensic case work in sub-Saharan Africa as well as for addressing larger issues regarding human variation and anthropological methodology.

\section{Materials and methods}

Crania of 520 individuals of known sex, age at death and ancestry were examined (Table 1). The average age at death of the sample was 51, with an age range of 18-90 (Table 2). Despite the 10-20 year age at death category, no juveniles were included in this study. The majority of the individuals were born in the early to middle part of the 20th century, with only 36 people born prior to 1900 and four after 1970 . The

Table 2

Age at death distribution of South African sample.

\begin{tabular}{lccc}
\hline Age range & Male & Female & Total \\
\hline $10-20^{\text {a }}$ & 5 & 4 & 9 \\
$21-30$ & 19 & 33 & 52 \\
$31-40$ & 47 & 33 & 80 \\
$41-50$ & 66 & 36 & 102 \\
$51-60$ & 62 & 38 & 100 \\
$61-70$ & 54 & 20 & 74 \\
$71-80$ & 39 & 13 & 52 \\
$81-90$ & 6 & 12 & 18 \\
Unknown & 14 & 19 & 33 \\
Total & 312 & 208 & 520 \\
\hline
\end{tabular}

a All samples $\geq 18$ years of age. sample was sourced from four modern 20th-century osteological collections in South Africa: the Pretoria Bone Collection (PBC), which is housed at the Department of Anatomy, University of Pretoria (Gauteng Province); the Kirsten Collection, which is stored in the Department of Anatomy at the Tygerberg Medical Campus, University of Stellenbosch (Cape Province); the Student Bone Collection, which is kept in the Department of Anatomy, Free State University (Free State Province); and the Raymond A. Dart Skeletal Collection, which is housed in the Department of Anatomical Sciences at the University of the Witwatersrand (Gauteng Province).

Thirteen non-metric traits from the face and jaw were scored. These traits were selected for two reasons. First, nine of these discrete traits, which were examined by Hefner [2] on North American groups, were shown to demonstrate a positive correlation with ancestry. Second, some of these variables - particularly those of the nasal and maxillary regions - are commonly used in South African forensic reports as a means to distinguish ancestral groups.

Standard definitions and illustrations for nine traits, namely nasal bone contour (also referred to as nasal bone structure), nasal aperture width, anterior nasal spine projection, inferior nasal aperture form, nasal overgrowth, malar tubercle, interorbital breadth, zygomaticomaxillary suture form, and transverse palatine suture shape, were taken from Hefner [2]. For detailed illustrations of these nine characters states, refer to Hefner [2]. Bass's [6] work was used to provide definitions of alveolar prognathism and zygomatic projection, white the definitions of Hauser and De Stephano [7] were used to score the presence or absence of the mandibular and palatine tori.

Brief definitions of these traits are presented in Table 3. In the nasal region, five discrete traits were analyzed, which included nasal bone contour, nasal aperture width, anterior nasal spine, inferior nasal margin, and nasal overgrowth. From the zygomatic and maxillary bones, another five discrete traits, namely the zygomatic projection, malar tubercle, interorbital breadth, zygomaxillary suture shape (Zs), and alveolar prognathism (Ap), were assessed. Three discrete traits were recorded on the mandible. These include the transverse palatine suture shape as well as the mandibular and palatine torus.

Statistical analyses were performed using SPSS version 11.5 for Windows and SAS PROCFREQ. Frequency distributions for each of the discrete traits and their corresponding character states were compiled for Black, White and "Coloured" South Africans.

To evaluate the relationship of the 13 discrete traits with ancestry, sex and age at death, ordinal regression was applied. In ordinal regression, the dependent variable is scored as categorical but nonetheless can be viewed as varying on a semicontinuous scale that is otherwise difficult to quantify precisely. For example, the character states for many non-metric skeletal traits vary from absent to weak to strong. Since, the typical discrete trait is scored in only 2,3 , or 4 character states, some of the assumptions of ANCOVA are violated. Ordinal regression (and the similar logistic regression procedure) allows one to analyze the variance structure of these traits in a fashion that is analogous to ANCOVA. These methods are more powerful than standard univariate and bivariate tests (such as Chi-squared and $t$ tests) because they allow for the simultaneous assessment of multiple independent variables, which helps to counter the sometimes subtle effects of unbalanced study samples and also permits one to examine higher order interactions between the variables.

In ordinal regression, the independent variables can be categorical (such as sex or ancestry) or continuous (such as age at death) [8]. Categorical and continuous independent variables can be combined in the same model. Interactions are assessed between two or more categorical independent variables, such as sex and ancestry, which can combine to affect the dependent variable in a way that neither variable does alone.

Ordinal regression calculates the log odds of the dependent variable, which is simply a transformation of the raw value of this variable. The application of maximum likelihood estimation transforms the dependent variable into a logit variable and in doing so the ordinal regression equation can be used to estimate the odds of a certain event occurring [8]

To measure inter- and intra-rater agreement, scores for the thirteen discrete traits were repeated on 30 skulls. The first (CVR) and second (ENL) observer scored these traits on two separate occasions. The strength of agreement between these scoring sessions was calculated using Cohen's Kappa statistic [9]. Agreement was determined to be excellent with a correlation coefficient greater than 0.75 , moderate when the correlation coefficient was between 0.40 and 0.74 , and poor when it was less than 0.40 . 
Table 3

Thirteen standard non-metric traits used in the study.

\begin{tabular}{|c|c|}
\hline Non-metric traits & Definition \\
\hline \multicolumn{2}{|l|}{ Nasal region } \\
\hline Nasal bone contour (nbc) & $\begin{array}{l}\text { The external surface contour of the nasal bones is observed and classified as quonset-hut (round) (0), oval ( } 1 \text { ), } \\
\text { tented (plateau) (2), semi-triangular (3), or steepled (triangular) (4) [5]. A nasal contour gauge, which was } \\
\text { employed by Hefner [2], was not used. }\end{array}$ \\
\hline Nasal aperture width (naw) & The width of the nasal opening was visually assessed and scored as narrow (1), medium (2), or wide (3) [2]. \\
\hline Anterior nasal spine (ans) & $\begin{array}{l}\text { This trait is scored with reference to an imaginary midsagittal line that runs from prosthion to nasion and ranges } \\
\text { from a short ( } 1 \text { ), to intermediate ( } 2 \text { ), to a pronounced ( } 3 \text { ) projection [2]. A short spine has no projection from the } \\
\text { nasal ridge; a dull spine has projection but does not pass beyond prosthion; whereas a pronounced spine projects } \\
\text { beyond prosthion [2]. }\end{array}$ \\
\hline Inferior nasal margin (inm) & $\begin{array}{l}\text { "The most inferior part of the nasal aperture, which, when combined with the lateral alae, constitutes the } \\
\text { transition from the nasal floor to the vertical portion of the maxilla, superior to the dentition" (Hefner [2]: p. 987). } \\
\text { Variants include a guttered appearance (1), incipient guttering (2), straight (3), transitioning to a partial sill (4), } \\
\text { and a complete sill (5) [2]. }\end{array}$ \\
\hline Nasal overgrowth (no) & $\begin{array}{l}\text { "Inferior projection of the lateral border of the nasal bones which is beyond the maxillae at nasale inferious" } \\
\text { (Hefner [2]: p. 989), which is scored as present (1) or absent (0). }\end{array}$ \\
\hline \multicolumn{2}{|l|}{ Zygomatic and maxilla } \\
\hline Zygomatic projection $(\mathrm{Zp})$ & $\begin{array}{l}\text { The observer holds the skull at the occipital region and places a pencil across the nasal aperture. From this } \\
\text { position, the observer evaluates the distance between the zygomatic bones and the pencil. In a non-projecting } \\
\text { zygoma (1) one can insert a finger between the zygomatic bone and the pencil. A retreating zygoma ( } 2 \text { ) refers to a } \\
\text { slight projection of the face towards the pencil. In a projecting zygoma (3) the observer is unable to insert a finger } \\
\text { between the zygomatic bone and the pencil; this is also referred to as a flat face [6]. }\end{array}$ \\
\hline Malar tubercle (Mt) & $\begin{array}{l}\text { This trait is a "caudally protruding tubercle located on the inferior margin of the maxilla and zygomatic bone" } \\
\text { (Hefner [2]: p. 988). In this instance, "a transparent ruler is placed at the intersection of the zygomatic suture and } \\
\text { the inferior margin of the malar bone to the deepest point on the curvature of the maxilla" (Hefner [2]: p. 988). } \\
\text { The ruler is then used as a plane of reference to score protrusion of the tubercle with respect to the } \\
\text { zygomaticomaxillary suture. A score of absent (0), incipient (1), trace (2), and present (3) is assigned to the } \\
\text { appearance of the malar tubercle. }\end{array}$ \\
\hline Interorbital breadth (ib) & $\begin{array}{l}\text { The distance from dacryon to dacryon is scored as narrow (1), intermediate (2), or broad (3) relative to the face } \\
\text { [2]. }\end{array}$ \\
\hline Zygomaxillary suture shape (Zs) & $\begin{array}{l}\text { This suture has three variants: angled }(0) \text {, smooth }(1) \text {, and s-shaped (2). An angled suture has the greatest lateral } \\
\text { projection near the midline, a smooth suture has a lateral projection at the inferior terminus, and an } s \text {-shaped } \\
\text { suture has a zig-zag appearance across the maxillary bone [2]. }\end{array}$ \\
\hline Alveolar prognathism (Ap) & $\begin{array}{l}\text { According to Bass [6], the observer takes a pencil and places it "on or near the anterior nasal spine, at the midline } \\
\text { of the skull, and at the base of the nasal aperture". The pencil is then lowered "towards the face until it touches } \\
\text { the menton" (Bass [6]: p. 92). In doing so, the observer records either a flat (1) or prognathic (2) face, which is one } \\
\text { that projects beyond the plane of the nasal bones [6]. }\end{array}$ \\
\hline \multicolumn{2}{|r|}{ p } \\
\hline Transverse palatine suture shape (Tp) & $\begin{array}{l}\text { The medial half of the transverse palatine suture is scored and has four character states, which include: a straight } \\
\text { symmetrical suture that intersects the palate perpendicular to the median palatine suture and does not deviate } \\
\text { from the midline }(0) \text {; an anteriorly symmetrical suture, which crosses the median palatine and deviates } \\
\text { anteriorly at the midline juncture (1); the anterior and posterior deviation of the suture at the midline (2); and } \\
\text { the posteriorly symmetrical deviation of the suture at the midline (3) [2]. }\end{array}$ \\
\hline Mandibular torus (Mdt) & $\begin{array}{l}\text { A protrusion of bone may be observed on the lingual surface of the mandible with the center over the root of the } \\
\text { mandibular second molar [7]. The trait is scored as present (1) or absent (0). }\end{array}$ \\
\hline Palatine torus (pt) & $\begin{array}{l}\text { A cigar-shaped ridge of bone may be observed on the midline of the hard palate and may vary in size, form and } \\
\text { extent [7]. This trait is scored as present (1) or absent (0). }\end{array}$ \\
\hline
\end{tabular}

Ethical approval for this study was obtained from the Student Ethics Committee of the University of Pretoria (S212/2007).

\section{Results}

Frequency distributions of the thirteen traits for White, Black and "Coloured" South Africans are presented in Table 4. Scores for Black and "Coloured" South Africans were predominantly distributed into the African or Asian groups for nasal bone contour, anterior nasal spine, and the inferior nasal margin; white South Africans also fell in the European categories for these variables. For the other discrete traits, the frequency distribution of South African groups was highly variable and did not correspond with traditional classifications.

A summary of the ordinal regressions is provided in Table 5. Except for the shape of the transverse palatine suture, all the discrete traits were shown to have a statistically significant relationship with ancestry. Sex significantly affected only one variable, inter-orbital breadth, and age at death affected two (anterior nasal spine and alveolar prognathism). With the advancement of age, the anterior nasal spine was more often scored as long, whereas alveolar prognathism was more often scored as absent. The interaction of ancestry and sex indepen- dently affected three variables (nasal bone contour, nasal breadth, and interorbital breadth). The test by itself is not able to show the amount or direction of this influence among the groups, and post hoc tests are necessary to tease out the details.

In Table 6, the cross-tabulations for the interactions between sex and ancestry for nasal bone contour, nasal aperture width and inter-orbital breadth are shown. Irrespective of ancestry, males exhibited a greater number of intermediate and wide scores for inter-orbital breadth than females. Black and "Coloured" males were more likely to present hut or tented nasal shapes, intermediate nasal aperture widths, and wide inter-orbital breadths than either Black or "Coloured" females. No differences in sex were observed for white South Africans and these discrete variables. The absence of sex differences for white South Africans can be attributed to differences in sexual dimorphism between populations.

A summary of intra- and inter-rater agreement, $p$-values, the Kappa statistic, as well as the percentage of agreement and its interpretation are provided in Table 7. Seven variables, which include the nasal bone contour, nasal aperture width, nasal overgrowth, anterior nasal spine, inferior nasal margin, interorbital breadth and malar tubercle had moderate to excellent repeatability for both observers. However, the other six variables - 
G Model

Table 4

Frequency distribution of non-metric traits associated with the nose and face in three South African groups.

\begin{tabular}{|c|c|c|c|c|c|}
\hline \multirow{2}{*}{\multicolumn{2}{|c|}{$\frac{\text { Non-metric trait }}{\text { Nasal bone contour }}$}} & & \multicolumn{3}{|c|}{ Ancestry groups: South Africa } \\
\hline & & & \multirow{2}{*}{$\begin{array}{l}\text { Black }(n=183) \\
44 \%(80)\end{array}$} & \multirow{2}{*}{$\begin{array}{c}\text { White }(n=129) \\
4 \%(5)\end{array}$} & \multirow{2}{*}{$\begin{array}{l}\text { “Coloured" }(n=95) \\
39 \%(37)\end{array}$} \\
\hline 0 & Quonset-hut & African & & & \\
\hline 1 & Hut & Asian & $34 \%(63)$ & $3 \%(4)$ & $36 \%(34)$ \\
\hline 2 & Tented & European & $15 \%(28)$ & $19 \%(25)$ & $16 \%(15)$ \\
\hline 3 & Vaulted & European & $4 \%(7)$ & $36 \%(47)$ & $5 \%(5)$ \\
\hline 4 & Steepled & European & $3 \%(5)$ & $37 \%(48)$ & $4 \%(4)$ \\
\hline \multicolumn{2}{|c|}{ Non-metric trait } & & \multicolumn{3}{|c|}{ Ancestry groups: South Africa } \\
\hline \multicolumn{2}{|c|}{ Nasal aperture width } & & Black $(n=229)$ & White $(n=148)$ & “Coloured" $(n=122)$ \\
\hline 1 & Long & European & $0.4 \%(1)$ & $43 \%(63)$ & $4 \%(5)$ \\
\hline 2 & Rounded & Asian & $87 \%(200)$ & $56 \%(84)$ & $92 \%(112)$ \\
\hline 3 & Wide & African & $12 \%(28)$ & $1 \%(1)$ & $4 \%(5)$ \\
\hline \multicolumn{2}{|c|}{ Non-metric trait } & & \multicolumn{3}{|c|}{ Ancestry groups: South Africa } \\
\hline \multicolumn{2}{|c|}{ Anterior nasal spine } & & Black $(n=233)$ & White $(n=149)$ & “Coloured" $(n=118)$ \\
\hline 0 & Short & African & $42 \%(97)$ & $7 \%(11)$ & $43 \%(50)$ \\
\hline 1 & Dull & Asian & $34 \%(79)$ & $5 \%(8)$ & $38 \%(45)$ \\
\hline 2 & Medium & European & $20 \%(47)$ & $26 \%(39)$ & $14 \%(17)$ \\
\hline 3 & Long & & $4 \%(10)$ & $61 \%(91)$ & $5 \%(6)$ \\
\hline \multicolumn{2}{|c|}{ Non-metric trait } & & \multicolumn{2}{|c|}{ Ancestry groups: South Africa } & \\
\hline \multicolumn{2}{|c|}{ Inferior nasal margin } & & Black $(n=234)$ & White $(n=157)$ & “Coloured" $(n=122)$ \\
\hline 0 & Guttered & African & $40 \%(93)$ & $8 \%(12)$ & $28 \%(34)$ \\
\hline 1 & Incipient guttering & African & $15 \%(34)$ & $2 \%(3)$ & $17 \%(21)$ \\
\hline 2 & Straight & Asian & $5 \%(12)$ & $3 \%(5)$ & $4 \%(5)$ \\
\hline 3 & Partial sill & European & $22 \%(52)$ & $7 \%(11)$ & $32 \%(39)$ \\
\hline 4 & Sill & European & $18 \%(43)$ & $80 \%(126)$ & $19 \%(23)$ \\
\hline \multicolumn{2}{|c|}{ Non-metric trait } & & \multicolumn{2}{|c|}{ Ancestry groups: South Africa } & \\
\hline \multicolumn{2}{|c|}{ Nasal overgrowth } & & Black $(n=171)$ & White $(n=122)$ & “Coloured" $(n=78)$ \\
\hline 0 & Absent & Eur/Afr & $35 \%(60)$ & $13 \%(16)$ & $50 \%(39)$ \\
\hline 1 & Present & Asian & $65 \%(111)$ & $87 \%(106)$ & $50 \%(39)$ \\
\hline & & & Ancestry groups: Sou & & \\
\hline & tion & & Black $(n=219)$ & White $(n=149)$ & "Coloured" $(n=119)$ \\
\hline 1 & Retreating & Eur/African & $86 \%(189)$ & $91 \%(135)$ & $73 \%(87)$ \\
\hline 2 & Projection & Asian & $14 \%(31)$ & $9 \%(14)$ & $27 \%(32)$ \\
\hline & & & Ancestry groups: Sout & & \\
\hline & & & Black $(n=214)$ & White ( $n=139)$ & “Coloured" $(n=111)$ \\
\hline 0 & Absent & African & $37 \%(80)$ & $80 \%(111)$ & $35 \%(39)$ \\
\hline 1 & Incipient & Asian & $56 \%(119)$ & $18 \%(25)$ & $55 \%(61)$ \\
\hline 2 & Trace & European & $2 \%(5)$ & $0 \%(0)$ & $6 \%(7)$ \\
\hline 3 & Present & & $4 \%(10)$ & $2 \%(3)$ & $4 \%(4)$ \\
\hline & & & Ancestry groups: Sou & & \\
\hline & th & & Black $(n=237)$ & White $(n=158)$ & “Coloured" $(n=125)$ \\
\hline 1 & Narrow & European & $3 \%(7)$ & $37 \%(58)$ & $7 \%(9)$ \\
\hline 2 & Intermediate & Asian & $55 \%(131)$ & $51 \%(81)$ & $66 \%(82)$ \\
\hline 3 & Wide & African & $42 \%(99)$ & $12 \%(19)$ & $27 \%(34)$ \\
\hline & & & Ancestry groups: Sou & & \\
\hline & ture shape & & Black $(n=188)$ & White $(n=131)$ & “Coloured" $(n=99)$ \\
\hline 1 & Angled & African & $22 \%(41)$ & $49 \%(65)$ & $24 \%(24)$ \\
\hline 2 & Smooth & Asian & $76 \%(143)$ & $49 \%(65)$ & $73 \%(72)$ \\
\hline 3 & S-shaped & European & $2 \%(4)$ & $2 \%(1)$ & $3 \%(3)$ \\
\hline & & & Ancestry groups: So & & \\
\hline & hism & & Black $(n=187)$ & White $(n=113)$ & "Coloured" $(n=86)$ \\
\hline 1 & Orthognathic & Eur/Asian & $43 \%(81)$ & $87 \%(98)$ & $63 \%(53)$ \\
\hline 2 & Prognathic & African & $57 \%(106)$ & $13 \%(15)$ & $38 \%(33)$ \\
\hline & & & Ancestry group & frica & \\
\hline & ne suture shape & & Black $(n=196)$ & White $(n=130)$ & “Coloured" $(n=93)$ \\
\hline 0 & Straight Asian & $16 \%(32)$ & $18 \%(23)$ & $18 \%(17)$ & \\
\hline 1 & Ant bulging African & $8 \%(15)$ & $7 \%(9)$ & $10 \%(9)$ & \\
\hline 2 & Scalaris European & $50 \%(99)$ & $50 \%(66)$ & $48 \%(45)$ & \\
\hline
\end{tabular}


Table 4 (Continued)

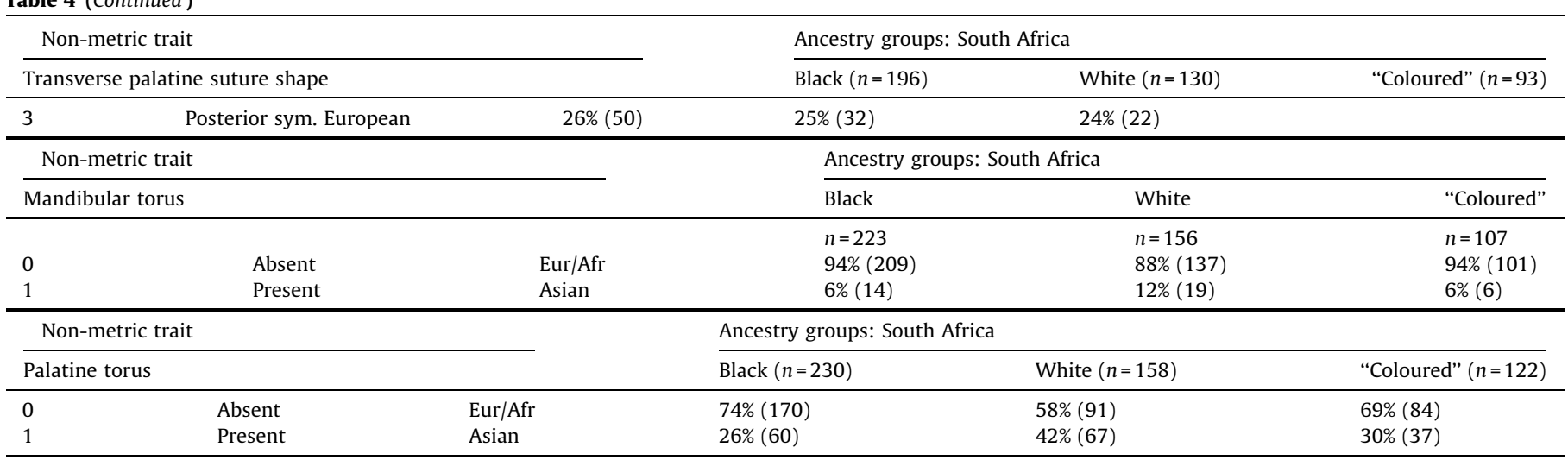

Table 5

Summary of ordinal regression results for twelve non-metric traits associated with ancestry in three South African groups.

\begin{tabular}{lllll}
\hline Non-metric trait & Ancestry & Sex & Age & Sex $\times$ Anc \\
\hline Nasal bone contour & ${ }^{* *}$ & $\mathrm{~ns}$ & $\mathrm{~ns}$ & ${ }^{*}$ \\
Nasal aperture width & ${ }^{* *}$ & $\mathrm{~ns}$ & $\mathrm{~ns}$ & ${ }^{*}$ \\
Anterior nasal spine & $* *$ & $\mathrm{~ns}$ & & $\mathrm{~ns}$ \\
Inferior nasal margin & ${ }^{* *}$ & $\mathrm{~ns}$ & $\mathrm{~ns}$ & $\mathrm{~ns}$ \\
Nasal overgrowth & ${ }^{* *}$ & $\mathrm{~ns}$ & $\mathrm{~ns}$ & $\mathrm{~ns}$ \\
Zygomatic projection & ${ }^{* *}$ & $\mathrm{~ns}$ & $\mathrm{~ns}$ & $\mathrm{~ns}$ \\
Malar tubercle & ${ }^{* *}$ & $\mathrm{~ns}$ & $\mathrm{~ns}$ & $\mathrm{~ns}$ \\
Interorbital breadth & ${ }^{* *}$ & ${ }^{*}$ & $\mathrm{~ns}$ & ${ }^{* *}$ \\
Zygomaxillary suture shape (9) & ${ }^{* *}$ & $\mathrm{~ns}$ & $\mathrm{~ns}$ & $\mathrm{~ns}$ \\
Alveolar prognathism & ${ }^{* *}$ & $\mathrm{~ns}$ & & $\mathrm{~ns}$ \\
Mandibular torus & ${ }^{* *}$ & $\mathrm{~ns}$ & $\mathrm{~ns}$ & $\mathrm{~ns}$ \\
Palatine torus & ${ }^{* *}$ & $\mathrm{~ns}$ & $\mathrm{~ns}$ & $\mathrm{~ns}$ \\
Transverse palatine suture shape (11) & $\mathrm{ns}$ & $\mathrm{ns}$ & $\mathrm{ns}$ & $\mathrm{ns}$
\end{tabular}

ns, not significant.

${ }^{*} p<0.05$.

$p<0.001$.

zygomatic suture shape, zygomatic projection, alveolar prognathism, mandibular torus, palatine torus and transverse suture shape - had poor consistency between observers. The statistically significant $p$-values for intra-and inter-observer scores mean that the observers assigned different character states for these discrete traits during the repeated trials.

\section{Discussion}

The estimation of ancestry forms a critical component of the biological profile. In biologically diverse countries like South Africa, knowledge of ancestry can be potentially useful in reducing the number of victims from a list of missing persons.

Forensic anthropologists and pathologists often use the traditional experience-based approach for estimating ancestry. The method involves the scoring of a series of discrete traits on the cranium. One or more of these traits are then combined to assign a classification of European, African, and Asian [10]. The problem with this technique is that it is not reliable, not accurate and cannot explain human variation within a population [2].

Stewart [11] was the first to address the possibility that a greater amount of variation existed among socially defined North American groups. However, his advice to forensic anthropologists was to rely on their personal experience as a means to determine the ancestry of an unknown person. Anthropologists followed this approach in North America and worldwide, and any overlap of discrete traits found in a cranium was explained as admixture between populations.

Current theory in human skeletal biology suggests that substantial variation exists in all human groups. Furthermore,
Table 6

Cross tabulation for the interaction between sex and ancestry for nasal bone contour, nasal aperture width and inter-orbital breadth.

\begin{tabular}{|c|c|c|c|c|c|}
\hline \multirow{2}{*}{$\begin{array}{l}\text { Non-metric traits with } \\
\text { character states }\end{array}$} & \multirow[t]{2}{*}{ Sex } & \multicolumn{3}{|c|}{ Groups } & \multirow[t]{2}{*}{ Total } \\
\hline & & Black & “Coloured" & White & \\
\hline \multicolumn{6}{|l|}{ Nasal bone contour } \\
\hline \multirow[t]{3}{*}{0 (Quonset-hut) } & $\mathrm{F}$ & 48 & 21 & 3 & 72 \\
\hline & M & 32 & 16 & 2 & 50 \\
\hline & & 80 & 37 & 5 & 122 \\
\hline \multirow[t]{3}{*}{1 (Hut) } & $\mathrm{F}$ & 21 & 7 & 1 & 29 \\
\hline & M & 42 & 27 & 3 & 72 \\
\hline & & 63 & 34 & 4 & 101 \\
\hline \multirow[t]{3}{*}{2 (Tented) } & $\mathrm{F}$ & 5 & 5 & 15 & 25 \\
\hline & M & 23 & 10 & 10 & 43 \\
\hline & & 28 & 15 & 25 & 68 \\
\hline \multirow[t]{3}{*}{3 (Vaulted) } & $\mathrm{F}$ & 4 & 1 & 18 & 23 \\
\hline & M & 3 & 4 & 29 & 36 \\
\hline & & 7 & 5 & 47 & 59 \\
\hline \multirow[t]{3}{*}{4 (Steepled) } & $\mathrm{F}$ & 2 & 0 & 23 & 25 \\
\hline & M & 3 & 4 & 25 & 32 \\
\hline & & 5 & 4 & 48 & 57 \\
\hline \multicolumn{6}{|l|}{ Nasal aperture width } \\
\hline \multirow[t]{3}{*}{1 (Narrow) } & $\mathrm{F}$ & 1 & 1 & 34 & 36 \\
\hline & M & 0 & 4 & 29 & 33 \\
\hline & & 1 & 5 & 63 & 69 \\
\hline \multirow[t]{3}{*}{2 (Intermediate) } & $\mathrm{F}$ & 80 & 34 & 35 & 149 \\
\hline & M & 120 & 78 & 49 & 247 \\
\hline & & 200 & 112 & 84 & 396 \\
\hline \multirow[t]{3}{*}{3 (Wide) } & $\mathrm{F}$ & 14 & 3 & 0 & 17 \\
\hline & M & 14 & 2 & 1 & 17 \\
\hline & & 28 & 5 & 1 & 34 \\
\hline \multicolumn{6}{|l|}{ Inter-orbital breadth } \\
\hline \multirow[t]{3}{*}{1 (Narrow) } & $\mathrm{F}$ & 2 & 3 & 32 & 37 \\
\hline & M & 5 & 6 & 26 & 37 \\
\hline & & 7 & 9 & 58 & 74 \\
\hline \multirow[t]{3}{*}{2 (Intermediate) } & $\mathrm{F}$ & 52 & 22 & 33 & 107 \\
\hline & M & 79 & 60 & 48 & 187 \\
\hline & & & 82 & 81 & 294 \\
\hline \multirow[t]{3}{*}{3 (Wide) } & $\mathrm{F}$ & 46 & 14 & 4 & 64 \\
\hline & M & 53 & 20 & 15 & 88 \\
\hline & & & 34 & 19 & 152 \\
\hline
\end{tabular}

culture, language, ecology and geography have been shown to influence the pattern and direction of this variation in both modern and historical populations [3,12-14]. In other words, sex, age at death, and date of birth also contribute to the variation that is observed in and between groups.

In a study of non-metric trait variation among White, Black and Native Americans, Hefner [2] demonstrated that ten traits - the anterior nasal spine, inferior nasal aperture, inter-orbital breadth, malar tubercle, nasal aperture width, nasal bone contour, nasal overgrowth, post-bregmatic depression, supra-nasal suture, and the transverse palatine - were significantly correlated with 
Table 7

Kappa statistic for 13 non-metric traits.

\begin{tabular}{|c|c|c|c|}
\hline Intra-observer error & $\%$ & Kappa & $p$-Value \\
\hline \multicolumn{4}{|l|}{ Excellent } \\
\hline Anterior nasal spine & 87 & 0.81 & ns \\
\hline \multicolumn{4}{|l|}{ Moderate } \\
\hline Nasal bone structure & 83 & 0.74 & ns \\
\hline Nasal breadth & 83 & 0.68 & ns \\
\hline Nasal overgrowth & 77 & 0.64 & ns \\
\hline Inferior nasal margin & 77 & 0.58 & \\
\hline Zygomatic projection & 87 & 0.55 & ns \\
\hline Malar tubercle & 73 & 0.53 & ns \\
\hline Inter-orbital breadth & 70 & 0.53 & \\
\hline \multicolumn{4}{|l|}{ Poor } \\
\hline Zygomatic suture shape & 63 & 0.39 & ns \\
\hline Alveolar prognathism & 50 & 0.25 & \\
\hline Mandibular torus & 80 & 0.16 & ns \\
\hline Palatine torus & 37 & 0.06 & \\
\hline Inter-observer error & $\%$ & Kappa & $p$-Value \\
\hline \multicolumn{4}{|l|}{ Moderate } \\
\hline Nasal overgrowth & 83 & 0.73 & ns \\
\hline Inferior nasal margin & 80 & 0.65 & ns \\
\hline Nasal breadth & 70 & 0.56 & ${ }^{*}$ \\
\hline Anterior nasal spine & 70 & 0.55 & ${ }^{*}$ \\
\hline Nasal bone structure & 70 & 0.54 & ns \\
\hline Inter-orbital breadth & 63 & 0.44 & ns \\
\hline Malar tubercle & 67 & 0.44 & \\
\hline \multicolumn{4}{|l|}{ Poor } \\
\hline Transverse palatine suture & 60 & 0.38 & $*$ \\
\hline Alveolar prognathism & 57 & 0.36 & ${ }^{*}$ \\
\hline Zygomatic projection & 83 & 0.25 & ns \\
\hline Zygomatic suture shape & 50 & 0.11 & ${ }^{*}$ \\
\hline Palatine torus & 37 & 0.06 & ** \\
\hline Mandibular torus & 77 & _- & ns \\
\hline
\end{tabular}

$\%$, agreement; ns, not significant.

${ }^{*} p<0.05$.

$p<0.001$.

ancestry. In addition, a large amount of within-group variation was observed for each trait.

A large amount of within-group variation is normal for a population, and, according to Hefner [2], nullifies the application of experienced-based morphological methods for the estimation of ancestry; especially when the observer relies too heavily on the assumption that there are marked trait differences between groups.

The distribution of variation of thirteen discrete traits for Black, White and "Coloured" South Africans contributes to our knowledge and understanding of human variation. Similar to Hefner's study [2], these discrete traits were shown to have both a large amount of within-group variation and to have a statistically significant relationship with ancestry. In addition, this study also showed that sex, age, and the interaction of sex and ancestry also influenced the variation found within some of these discrete traits. With regard to age at death, the presence of alveolar prognathism decreased with increasing age in the sample, whereas the length of the anterior nasal spine increased with increasing age. These results may be a consequence of the older persons in the sample for whom tooth loss and alveolar bone resorption would have contributed to changes in their facial morphology.

Another interpretation for these results is that non-metric traits are not valid assessors of biological variation in a population $[15,16]$. Researchers have shown that non-metric trait expression can be attributed to a combination of genetics and environmental influences [15-17]. But, no clear consensus is available as to which factor, genetics or environment, is more contributory to the morphological expression of a discrete trait [16]. Furthermore, the genetic inheritance of a trait has been shown to have little to do with its visible appearance in a group [15].
Forensic anthropologists frequently use discrete traits to justify biological separation between groups. Yet, many researchers are unsure about these traits being valid measures in discerning population differences, particularly among admixed groups such as "Coloured" South Africans [15-18].

In a study on Native Americans associated with the Pete Klunk Mound group, Koningsberg [17] noted that discrete traits did not change in frequency or distribution across temporal groups. The traits were shown to be heritable, but they did not significantly contribute to the biological variation in the population. Unlike osteometric stature or sexual dimorphism, they were not population specific. Similarly in a study on discrete traits and familial (genetic) relationships, Ricaut et al. [18] found positive albeit low - correlations between the two variables. In line with other researchers, they cautioned the use of discrete traits as a means to explain assumed genetic differences between groups.

In this study, the relative equal distribution of discrete traits used to evaluate ancestry among three South African groups offers some support to these studies on discrete trait analysis. However, when compared to Hefner's [2] North American groups, South Africans are more genetically heterogeneous. This inherent heterogeneity, due to migration, gene flow and historical circumstances, may also explain the lack of separation of these traits among the three groups.

These results suggest that anthropologists cannot visually differentiate populations based on individual discrete morphological traits. Multi-variate analyses, such as "logistic regression, naive Bayesian and k-Nearest neighbour", have been suggested as a better approach to quantify and to describe differences within and between populations ([2]:p. 994).

In previous decades, scholars often assumed that non-metric traits were easy to replicate [19], but in later years, it was found that poor definitions lead to inaccuracies in repeatability of the character states [2]. In this study, several traits, including zygomatic suture shape, zygomatic projection, transverse palatine suture shape as well as the presence or absence of alveolar prognathism, the mandibular torus, and the palatine torus were shown not to be repeatable between observers. A possible explanation for this may be a poor description of the traits, or that the trait descriptions do not fit the populations to which they are applied. These issues may have affected the correct selection of these variables and thus explain the large differences in intra and inter-rater repeatability. The remaining traits, which were obtained from Hefner [2], were repeatable and should be used in future non-metric studies evaluating ancestry.

\section{Conclusion}

The distribution of discrete traits in a South African sample was shown to be highly variable. Yet, despite considerable withingroup variation, these discrete traits had a statistically significant relationship with ancestry. This outcome supports previous work done by Hefner [2] on North American populations. Therefore, the application of the traditional experience-based approach for estimating ancestry is not a reliable approach for forensic case work in South Africa. Rather, the non-metric evaluation of ancestry needs to be based on statistical analyses from which known accuracy and reliability values can be obtained [2,3].

\section{Acknowledgements}

ENL would like to thank the National Research Foundation (NRF) and NAVKOM at the University of Pretoria who provided financial assistance. Professor BJ Page (University of Stellenbosch), Professor Elsa de Wit (University of the Free State), Ms. Nalini Pather (Raymond A. Dart Collection), and Mrs. Malebo Marebane/ 
Mr. Marius Loots (Pretoria Bone Collection) gave information about and access to the four skeletal collections. Professor D. Roussouw, Professor G. Dreyer and Ms. B. English of the University of Pretoria, as well as the anonymous reviewers, provided helpful commentary and editorial advice.

\section{References}

[1] A.H. Ross, E.H. Slice, D.H. Ubelaker, A.B. Falsetti, Population affinities of 19th century Cuban crania: implications for identification criteria in South Florida Cuban Americans, J. Forensic Sci. 49 (2004) 11-16.

[2] J.T. Hefner, Cranial non-metric variation and estimating ancestry, J. Forensic Sci. 54 (2009), 985-959

[3] S.D. Ousley, R. Jantz, D. Fried, Understanding race and human variation: why forensic anthropologists are good at identifying race, Am. J. Phys. Anthrop. 139 (2009) 68-76.

[4] C.L. Brace, K.D. Hunt, A non-racial craniofacial perspective on human variation, Am. J. Phys. Anthrop. 82 (1990) 341-360.

[5] A.M. Brues, The once and future diagnosis of race, in: G.W. Gills, S. Rhine (Eds.), Skeletal Attribution of Race: Methods for Forensic Anthropology. Maxwell Museum of Anthropology: Anthropological Papers No. 4, 1990, pp. 1-4.

[6] W.M. Bass, in: M.K. Trimble (Ed.), Human Osteology: A Laboratory and Field Manual, Missouri Archaeological Society, Columbia, 1995.

[7] G. Hauser, G.F. De Stefano, Epigenetic Variants of the Human Skull, Schweizerbart, Stuttgart, 1989.

[8] P. McCullagh, Regression models for ordinal data, J. Roy. Stat. Soc. Ser. B (Methodological) 42 (1980) 109-142.
[9] M. Banerjee, M. Cappozzoli, M. McSweeny, D. Sinha, Beyond Kappa: a review of inter-rater agreement measures, Can. J. Stat 27 (1999) 3-23.

[10] S. Rhine, Non-metric skull racing, in: G.W. Gill, S. Rhine (Eds.), Skeletal Attribution of Race: Methods for Forensic Anthropology, Maxwell Museum of Anthropological Papers No. 4, 1990, pp. 9-20.

[11] T.D. Stewart, Attribution of Race in Essentials of Forensic Anthropology: Especially as Developed in the United States, Charles C. Thomas, Springfield, 1979.

[12] H.J.H. Edgar, K.L. Hunley, Race reconciled? How biological anthropologists view human variation, Am. J. Phys. Anthrop. 139 (2009) 1-4.

[13] H.J.H. Edgar, Biohistorical approaches to 'race' in the US: Biological distances among African Americans, European Americans, and their ancestors, Am. J. Phys. Anthrop. 139 (2009) 58-67.

[14] S.D. Ousley, E.N. L'Abbé, Craniometric variation in South African and American Blacks, 62nd AAFS Abstract H66 (2010) 377.

[15] J.M. Cheverud, J.E. Buikstra, Quantitative genetics of skeletal non-metric traits in Rhesus Macaques on Cayo Santiago. II. Phenotypic, genetic and environmental correlations between traits, Am. J. Phys. Anthrop. 54 (1981) 51-58.

[16] J.M. Cheverud, J.E. Buikstra, Quantitative genetics of skeletal nonmetrics traits in the Rhesus Macaques of Cayo Santiago. III. Relative heritability of skeletal nonmetric and metric traits, Am. J. Phys. Anthrop. 59 (1982) 151-155.

[17] L.W. Konigsberg, Temporal aspects of biological distance: serial correlation and trend in a pre-historic skeletal lineage, Am. J. Phys. Anthrop. 82 (1990) 45-52.

[18] F.X. Ricaut, V. Auriol, N. Cramon-Taubadel, C. Keyser, P. Murail, B. Ludes, E. Crubézy, Comparison between morphological and genetic data to estimate biological relationship: the case of Egyin Gol necropolis, Am. J. Phys. Anthrop. 143 (2010) 355-364.

[19] R.S. Corruccini, An examination of the meaning of cranial discrete traits for human skeletal biological studies, Am. J. Phys. Anthrop. 40 (1974) 425-446. 